\title{
THE INFLUENCE OF THE SELECTION SYSTEM, TRAINING AND JOB SATISFACTION ON EMPLOYEES PERFORMANCE ON PT LION AIR GROUP OF MUTIARA SIS AL-JUFRI PALU AIRPORT BEFORE THE PANDEMIC COVID 19
}

\author{
Rika Suprapty ${ }^{1}$ \\ Email: rikasu.hidar@gmail.com \\ R Syamsuddin ${ }^{2}$ \\ Email:syamris60@gmail.com \\ Maria Asri ${ }^{3}$ \\ Email: mariaasri262@gmail.com
}

\begin{abstract}
This study aims to determine and analyze the effect of the selection, training and employment systems. satisfaction both collectively and partially on the performance of employees at PT Lion Air Group from Mutiara Sis Al-Jufri Airport, Palu before the pandemic covid-19. Data was collected through direct observation and surveys by distributing questionnaires and interviews to employees of PT. Lion Air Group Mutiara Sis Al-Jufri Palu before the pandemic covid-19 to become a plague in Indonesia. The analytical method used is multiple linear regression analysis. The test results show that the selection system, training and job satisfaction, both simultaneously and partially have a significant effect on employee performance before the spread of the covid-19 pandemic in Indonesia.
\end{abstract}

Keywords: Selection System, Training, Job Satisfaction, Employee Performance and Covid 19

\section{LATAR BELAKANG}

Lion Air merupakan salah satu bagian dari Lion Air Group yang juga menaungi maskapai lainnya seperti Wings Air, Batik Air, Lion Bizjet, Malindo Air yang berbasis di Malaysia, dan Thai Lion Air yang berbasis di Thailand. Akhir-akhir ini banyak kasus yang terjadi pada PT. Lion Air Group, terlebih setelah merebaknya pandemic covid 19 yang menyebabkan PHK karyawan, pembatasan rute penerbangan, pengeluaran operasional yang tak terduga seperti biaya parkir pesawat dihanggar dan perpanjangan jangka waktu berlakunya pelatihan simulator maupun pemeriksaan kesehatan bagi awak pesawat.

\footnotetext{
${ }^{1}$ Corresponding author: STIE Panca Bhakti Palu, Besusu Barat, Palu Timur, Palu, Sulawesi Tengah, 94118

${ }^{2,3}$ STIE Panca Bhakti Palu, Besusu Barat, Palu Timur, Palu, Sulawesi Tengah, 94118
} 
PT. Lion Air Group Bandara Mutiara Sis Al-jufri Palu merupakan salah satu cabang perluasan jaringan usaha Lion Air, memiiki jumlah karyawan mencapai 136 orang.Dengan jumlah karyawan yang cukup banyak dan tanggung jawab yang besar sebagai salah satu perusahaan transportasi udara, maka diperlukan adanya perhatian khusus terhadap sumber daya manusia di dalamnya, peran penting sistem seleksi, pelatihan dan kepuasan kerja karyawan terlebih adanya pandemic covid 19 yang melanda Indonesia dan seluruh dunia sekarang ini yang membuat banyak maskapai penerbangan melakukan PHK dan merumahkan sebagian karyawan dan awak kabin. Dalam penelitian ini, mengambil data sebelum terjadinya wabah pandemic kasus covid 19, sehingga belum ada gambaran akan terjadinya wabah pandemic di awal tahun 2020 yang mengakibatkan PHK, merumahkan sebagian karyawan, pilot dan awak kabin Lion Air di Indonesia dan tak terkecuali pada PT Lion Air Group Bandara Mutiara Sis Al-Jufri Palu. Sehingga hasil penelitian ini, diharapkan memberikan gambaran umum yang factual terjadi dalam pengelolaan Manajemen Sumber Daya Manusia pada Maskapai Penerbangan Lion Air Group Bandara Mutiara Sis Al Jufri Palu dalam setahun terakhir.

Berdasarkan fenomena tersebut, maka penulis tertarik untuk melakukan penelitian dengan judul "Pengaruh Sistem Seleksi, Pelatihan dan Kepuasan Kerja Karyawan Terhadap Kinerja Karyawan PT. Lion Air Group Bandara Mutiara Sis AlJufri Palu sebelum Pandemic Covid 19", dengan rumusan masalah sebagai berikut: Apakah sistem seleksi, pelatihan dan kepuasan kerja kayawan berpengaruh terhadap kinerja karyawan pada PT. Lion Air Group Bandara Mutiara Sis Al-Jufri Palu sebelum pandemic covid 19 ?; Apakah sistem seleksi karyawan, berpengaruh terhadap kinerja karyawan pada PT. Lion Air Group Bandara Mutiara Sis Al-Jufri Palu sebelum pandemic covid 19?; Apakah pelatihan karyawan berpengaruh terhadap kinerja karyawan pada PT. Lion Air Group Bandara Mutiara Sis Al-Jufri Palu sebelum pandemic covid 19?; Apakah kepuasan kerja karyawan berpengaruh terhadap kinerja karyawan pada PT. Lion Air Group Bandara Mutiara Sis Al-Jufri Palu sebelum pandemic covid 19?. Sehingga tujuan penelitian ini adalah untuk mengetahui dan menganalisis pengaruh sistem seleksi, pelatihan dan kepuasan kerja kayawan terhadap kinerja karyawan pada PT. Lion Air Group Bandara Mutiara Sis Al-Jufri Palu sebelum pandemic covid 19?; Untuk mengetahui dan menganalisis pengaruh sistem seleksi karyawan terhadap kinerja karyawan pada PT. Lion Air Group Bandara Mutiara Sis Al-Jufri Palu sebelum pandemic covid 19?; Untuk mengetahui dan menganalisis pengaruh pelatihan karyawan terhadap kinerja karyawan pada PT. Lion Air Group Bandara Mutiara Sis Al-Jufri Palu sebelum pandemic covid 19? dan untuk mengetahui dan menganalisis pengaruh kepuasan kerja karyawan terhadap kinerja karyawan pada PT. Lion Air Group Bandara Mutiara Sis Al-Jufri Palu sebelum pandemic covid 19?

\section{TINJAUAN TEORITIS}

Pada umumnya, seleksi karyawan melalui serangkaian proses kegiatan penyeleksian dilakukan, agar mendapatkan karyawan yang tepat untuk mengisi posisi jabatan/pekerjaan dalam suatu perusahaan. Menurut Sunyoto (2012), "Seleksi tenaga kerja atau karyawan adalah merupakan serangkaian kegiatan yang dilaksanakan untuk memutuskan apakah seseorang pelamar diterima atau ditolak, dalam suatu instansi tertentu setelah menjalani serangkaian tes yang dilaksanakan". Menurut Nitisemito (2008) tujuan seleksi karyawan adalah untuk mendapatkan "The Right Man In The Right Place". Didalam proses seleksi perusahaan harus mendapatkan tenaga kerja 
yang tepat di dalam posisi yang tepat pula. Menjamin perusahaan memiliki karyawan yang tepat untuk suatu jabatan/pekerjaan. Dengan demikian, perusahaan akan mendapatkan karyawan yang memiliki kinerja yang baik, sesuai diharapkan perusahaan.

Sementara itu, Simamora (2004a) menjelaskan bahwa pelaksanaan proses seleksi "Perusahaan tentu akan mengharapkan para pelamar yang datang memiliki prestasi yang memuaskan dalam pekerjaannya". Dimensi pengukuran sistem seleksi terdiri dari a) Pendidikan, b.) Pengalaman kerja, c.) Kondisi fisik; d.) Kepribadian

Selain itu, untuk meningkatkan kinerja dapat pula dilakukan melalui program pendidikan dan pelatihan. Kurangnya perhatian terhadap pendidikan dan pelatihan kerja karyawan akan menghambat kinerja karyawan dan juga membuat produktivitas kerja rendah, maka dibutuhkan program pendidikan dan pelatihan yang dapat menimbulkan tingkat ketekunan dan kedisiplinan dalam melaksanakan suatu kegiatan sehingga membuat kinerja karyawan meningkat. Sebagaimana, dikemukan Ardana dalam Sunyoto (2012) "pengembangan karyawan juga penting untuk memenuhi tuntutan pekerjaan atau jabatan karena sebagai akibat kemajuan teknologi dan semakin ketatnya persaingan di antara perusahaan sejenis, perlu dilakukan pengembangan baik demi tujuan karier maupun non karier bagi para karyawan baru atau lama melalui pendidikan dan pelatihan". Sedangkan pengertian pelatihan menurut Mangkunegara (2006) adalah suatu proses pendidikan jangka pendek yang mempergunakan prosedur sistematik dan terorganisir dimana pegawai non manajerial mempelajari pengetahuan dan keterampilan teknis dalam tujuan terbatas. Dimensi pengukuran pelatihan adalah peserta, b.) materi, c.) metode pelatihan, d.) sarana pelatihan.

Faktor lain, yang dapat mendorong peningkatan kinerja karyawan adalah kepuasan kerja merupakan perwujudan perasaan yang dapat mencerminkan tingkatan kecintaanya terhadap pekerjaanya. Seorang karyawan akan lebih bersemangat dalam melaksanakan pekerjaannya bila ia mencintai dan menikmati pekerjaanya serta merasa puas akan apa yang didapatkan dari pekerjaanya tersebut. Kepuasan kerja karyawan adalah suatu bentuk perasaan emosional seseorang karyawan terhadap pekerjaannya. Semakin tinggi kemampuan karyawan dalam mengerjakan pekerjaan, semakin baik sikap dan minat karyawan terhadap pekerjaan maka kinerja karyawan semakin meningkat" Madegunastri dalam (Romel 2013). Menurut Hasibuan (2008), "Kepuasan kerja adalah sikap emosional yang menyenangkan dan mencintai pekerjaanya. Sikap ini di cerminkan oleh moral kerja, kedisiplinan, dan prestasi kerja." Berdasarkan defenisi tersebut, maka dimensi pengukuran kepuasan kerja yaitu menyenangi pekerjaannya, b.) Mencintai pekerjaannya, c.) Moral kerja, d.) Kedisiplinan, e.) Prestasi kerja.

Sedangkan Kinerja Karyawan atau prestasi kerja, menurut Mangkunegara (2009) adalah hasil kerja secara kualitas dan kuantitas yang dicapai seorang pegawai dalam melaksanakan tugasnya sesuai dengan tanggung jawab yang dibebankan kepadanya." Dimensi pengukuran kinerja karyawan adalah Kualitas, b.) Kuantitas, c.) Pelaksanaan tugas, d.) Tanggung jawab.

Dalam penelitian ini, mengambil data sebelum terjadinya wabah pandemic kasus covid 19, sehingga belum ada gambaran akan terjadinya wabah pandemic di awal tahun 2020 yang mengakibatkan PHK, merumahkan sebagian karyawan, pilot dan awak kabin Lion Air di Indonesia dan tak terkecuali pada PT Lion Air Group Bandara Mutiara Sis Al-Jufri Palu. Sehingga hasil penelitian ini diharapkan memberikan gambaran umum yang factual terjadi dalam pengelolaan Manajemen 
Sumber Daya Manusia pada Maskapai Penerbangan Lion Air Group Bandara Mutiara Sis Al Jufri Palu dalam setahun terakhir. Pada saat pengambilan data di lapangan, peneliti memiliki akses untuk menyebarkan kuesioner secara langsung pada responden yang menjadi sampel dalam penelitian.

Berdasarkan uraian teoritis tersebut, dapat dikemukanan kerangaka pemikiran penelitian sebagai berikut:

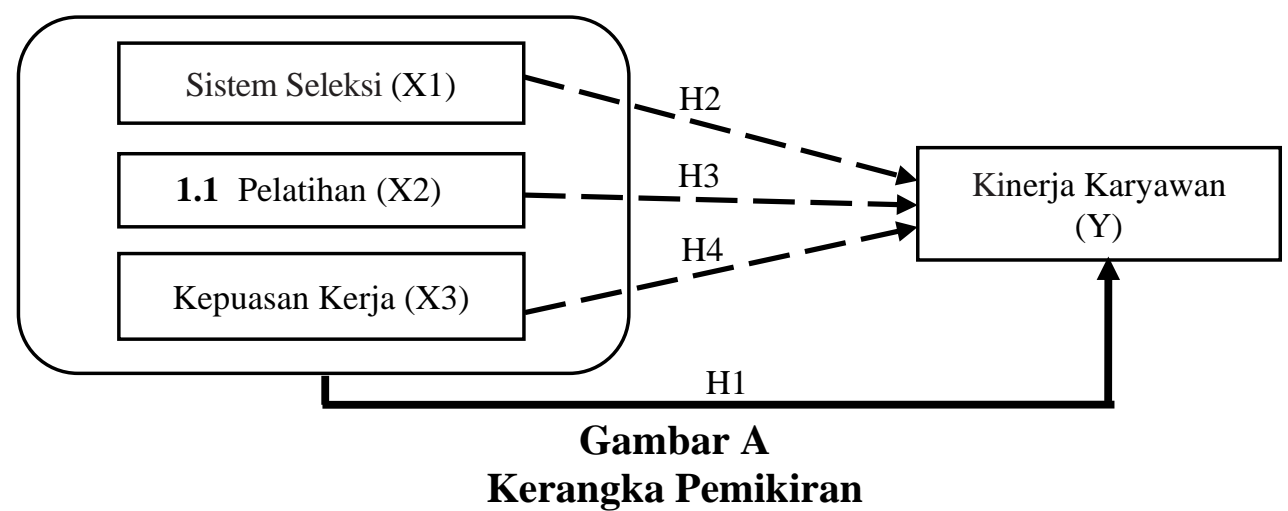

Keterangan :

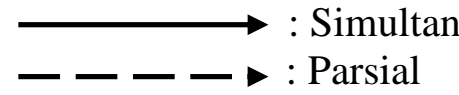

Berdasarkan uraian latar belakang, tinjauan pustaka, dan kerangka pemikiran di atas, maka hipotesis dalam penelitian ini adalah :

H1. Sistem seleksi, pelatihan dan kepuasan kerja kayawan secara simultan berpengaruh signifikan terhadap kinerja karyawan pada PT. Lion Air Group Bandara Mutiara Sis Al-Jufri Palu sebelum pandemic covid 19;

H2. Sistem seleksi karyawan secara parsial berpengaruh signifikan terhadap kinerja karyawan pada PT. Lion Air Group Bandara Mutiara Sis AlJufri Palu sebelum pandemic covid 19;

H3. Pelatihan karyawan secara parsial berpengaruh signifikan terhadap kinerja karyawan pada PT. Lion Air Group Bandara Mutiara Sis AlJufri Palu sebelum pandemic covid 19; dan

H4. Kepuasan kerja karyawan secara parsial berpengaruh signifikan terhadap kinerja karyawan pada PT. Lion Air Group Bandara Mutiara Sis Al-Jufri Palu sebelum pandemic covid 19.

\section{METODE PENELITIAN}

Penelitian yang dilakukan adalah pada PT. Lion Air Group Bandara Mutiara Sis Al-jufri Palu pada bulan Agustus 2018 dan akan dilanjutkan pada bulan Januari 2019, setahun sebelum merebaknya Pandemic Covid 19 di awal tahun 2020. Untuk memperoleh data yang dibutuhkan dilakukan observasi dan survey melalui penyebaran kuesioner, kepada responden sampel sebanyak 57 karayawan dari 136 karyawan PT. Lion Air Group Bandara Mutiara Sis Al-jufri Palu. Jumlah sampel ditetapkan berdasarkan rumus Slovin dan penarikan sampel menggunakan metode stratified proporsional random sampling terhadap dua kelompok karyawan yaitu pada bagian station Lion Air Group sebanyak 19 orang dan bagian ground handling 
sebanyak 38 orang. Berikut adalah gambaran matriks operasional variable penelitian ini:

Tabel 1

Matriks Operasional Variabel

\begin{tabular}{|c|c|c|c|c|c|}
\hline No & Variabel & Dimensi & Indikator & $\begin{array}{c}\text { Skala } \\
\text { Pengukuran }\end{array}$ & $\begin{array}{c}\text { Item } \\
\text { Pernyataan }\end{array}$ \\
\hline \multirow{4}{*}{1} & \multirow{4}{*}{$\begin{array}{c}\text { Sistem Seleksi } \\
\text { (XI) } \\
\text { (Simamora } \\
\text { 2004b) }\end{array}$} & - Pendidikan & $\begin{array}{ll}\text { - Minimal pendidiakan dan } \\
\text { Jenis pendidikan }\end{array}$ & \multirow{4}{*}{ likert } & $1-2$ \\
\hline & & $\begin{array}{l}\text { - Pengalaman } \\
\text { kerja }\end{array}$ & $\begin{array}{ll}\text { - Kemampuan } & \\
\text { - Sikap } & \text { terkait dengan } \\
\text { pekerjaan } & \end{array}$ & & $3-6$ \\
\hline & & - Kondisi fisik & $\begin{array}{l}\text { - Karakteristik fisik } \\
\text { - Efektifitas kerja }\end{array}$ & & $7-10$ \\
\hline & & - Kepribadian & $\begin{array}{l}\text { - Sikap yang dimiliki } \\
\text { seseorang dan karakteristik } \\
\text { pribadi }\end{array}$ & & $11-12$ \\
\hline \multirow{4}{*}{2} & \multirow{4}{*}{$\begin{array}{c}\text { Pelatihan } \\
\text { (X2) } \\
\text { (Mangkunegara } \\
\text { 2006) }\end{array}$} & - Peserta & $\begin{array}{l}\text { - Kualifikasi yang sesuai } \\
\text { - Semangat yang tinggi }\end{array}$ & \multirow{4}{*}{ likert } & $13-16$ \\
\hline & & - Materi & $\begin{array}{l}\text { - Materi atau kurikulum yang } \\
\text { sesuai } \\
\text { - Dapat memahami masalah }\end{array}$ & & $17-20$ \\
\hline & & $\begin{array}{l}\text { - metode } \\
\text { pelatihan }\end{array}$ & $\begin{array}{l}\text { - sesuai dengan jenis materi } \\
\text { - Komponen peserta } \\
\text { pelatihan }\end{array}$ & & $21-24$ \\
\hline & & $\begin{array}{l}\text { - sarana } \\
\text { pelatihan. }\end{array}$ & $\begin{array}{l}\text { - Fasilitas gedung, sarana } \\
\text { pembelajaran, makanan dan } \\
\text { minuman }\end{array}$ & & $25-26$ \\
\hline \multirow{5}{*}{3} & \multirow{5}{*}{$\begin{array}{l}\text { Kepuasan Kerja } \\
\text { (X3) (Hasibuan } \\
\text { 2008) }\end{array}$} & $\begin{array}{l}\text { - Menyenangi } \\
\text { pekerjaannya }\end{array}$ & $\begin{array}{l}\bullet \text { Mengerjakan tugas dengan } \\
\text { baik } \\
\text { - menyenangi pekerjaannya }\end{array}$ & \multirow{5}{*}{ Likert } & $27-30$ \\
\hline & & $\begin{array}{l}\text { - Mencintai } \\
\text { Pekerjaannya }\end{array}$ & $\begin{array}{l}\text { - Memberikan yang terbaik } \\
\text { - mencurahkan segala } \\
\text { kemampuan }\end{array}$ & & $31-34$ \\
\hline & & - Moral kerja & $\begin{array}{l}\text { - Kesepakatan batiniah } \\
\text { karyawan untuk melakukan } \\
\text { tugas dengan baik }\end{array}$ & & $35-36$ \\
\hline & & - Kedisiplinan & $\begin{array}{l}\text { - Ketaatan, kepatuhan, } \\
\text { kesetiaan, keteraturan dan } \\
\text { ketertiban. }\end{array}$ & & $37-38$ \\
\hline & & - Prestasi kerja & $\begin{array}{l}\text { - Hasil kerja yang dicapai } \\
\text { - kecakapan dan } \\
\text { kesungguhan }\end{array}$ & & $39-42$ \\
\hline \multirow{4}{*}{4} & \multirow{4}{*}{$\begin{array}{c}\text { Kinerja Karyawan } \\
\text { (Y) } \\
\text { (Mangkunegara } \\
\text { 2009) }\end{array}$} & • Kualitas & $\begin{array}{l}\text { - Seberapa baik karyawan } \\
\text { mengerjakan tugasnya }\end{array}$ & \multirow{4}{*}{ Likert } & $43-44$ \\
\hline & & - Kuantitas & - Kecepatan kerja & & $45-46$ \\
\hline & & $\begin{array}{l}\text { - Pelaksanaan } \\
\text { tugas }\end{array}$ & $\begin{array}{l}\text { - tujuan hasil yang terbaik } \\
\text { bagi pekerjaannya }\end{array}$ & & $47-48$ \\
\hline & & $\begin{array}{l}\text { - Tanggung } \\
\text { jawab }\end{array}$ & $\begin{array}{l}\text { - Kesadaran akan kewajiban } \\
\text { tugas }\end{array}$ & & $49-50$ \\
\hline
\end{tabular}

Sumber: Hasil Kajian Teori

Untuk menjawab permasalahan dan menguji hipotesis penelitian digunakan analisis statistik regresi linear berganda (multiple linear regression). Dengan formulasi matematis dalam bentuk persamaan sebagai berikut: 
Dimana :

$$
\mathrm{Y}=\mathrm{a}+\mathrm{b} 1 \mathrm{X} 1+\mathrm{b} 2 \mathrm{X} 2+\mathrm{b} 3 \mathrm{X} 3+\mathrm{e}
$$

\begin{tabular}{|c|c|}
\hline Y & = Kinerja Karyawan \\
\hline $\mathrm{X} 1$ & $=$ Sistem Seleksi \\
\hline $\mathrm{X} 2$ & $=$ Pelatihan \\
\hline X3 & $=$ Kepuasan Kerja \\
\hline A & $=$ Konstanta \\
\hline b1-b4 & $=$ Parameter yang diukur \\
\hline & $=$ ERROR (residual) \\
\hline
\end{tabular}

Untuk menguji keberartian dari koefosien regresi secara serempak digunakan uji-F dengan bentuk formulasi menurut Rangkuti (2007) sebagai berikut :

Dimana :

$$
F_{h}=\frac{R^{2} /(k-1)}{\left(1-R^{2}\right) /(n-k)}
$$

Fh = Nilai F-hitung

R2 = koefisien determinasi ganda

$\mathrm{k}=$ Jumlah variabel independen

$\mathrm{n} \quad=$ jumlah sampel

Untuk menguji pengaruh dari masing-masing variabel bebas secara parsial atau untuk mengetahui variabel mana yang relatif dominan berpengaruh terhadap variabel terikat digunakan uji t dengan rumus menurut Rangkuti (2007) sebagai berikut :

Dimana :

$$
t_{h}=\frac{b i}{S b i}
$$

th $\quad=$ Nilai t-hitung

bi $\quad=$ Parameter estimasi

Sbi $=$ Standar error

\section{HASIL DAN PEMBAHASAN}

Hasil analisis regresi linier berganda dengan menggunakan bantuan program Statistical Product and Service Solutions Release 16 for windows (SPSS 16) adalah sebagai berikut :

Tabel 2

Hasil Regresi Linear Berganda

Sumber : Hasil Pengolahan Dengan SPSS Statistic 16.0

\begin{tabular}{clcccc}
\hline No & \multicolumn{1}{c}{ Variabel } & $\begin{array}{c}\text { Koefisien } \\
\text { Regresi (Beta) }\end{array}$ & t & $\begin{array}{c}\text { Probabilitas } \\
\text { (Sig. t) }\end{array}$ & part \\
\hline 1 & (Constant) & 0,001 & 0,003 & 0,998 & \\
2 & Sistem Seleksi X & 0,278 & 2.109 & 0,040 & 0,278 \\
3 & Pelatihan $X_{2}$ & 0,280 & 2.131 & 0,038 & 0,281 \\
4 & Kepuasan Kerja $X_{3}$ & 0,298 & 2.353 & 0,022 & 0,308 \\
\hline Multiple R $=0,750$ & \multicolumn{2}{c}{ Adjusted R Square $=0,537$} & \\
F-hitung $=22,662$ & R Square & $=0,562$ & \\
T-tabel $\quad=2,005$ & F-tabel & $=2,78$ & \\
$\alpha$ & $=0,05$ & Sig & $=0,000$ & \\
\hline
\end{tabular}


Berdasarkan tabel di atas dapat diperoleh model persamaan regresi berikut :

$$
\begin{aligned}
& \mathrm{Y}=\mathrm{a}+\mathrm{b}_{1} \mathrm{X}_{1}+\mathrm{b}_{2} \mathrm{X}_{2}+\mathrm{b}_{3} \mathrm{X}_{3}+\mathrm{e} ; \text { atau } \\
& \mathrm{Y}=0,001+0,278 \mathrm{X}_{1}+0,280 \mathrm{X}_{2}+0,298 \mathrm{X}_{3}
\end{aligned}
$$

1. Nilai Konstanta $\mathrm{a}=0,001$ menunjukan bahwa sistem seleksi $\left(\mathrm{X}_{1}\right)$, pelatihan $\left(\mathrm{X}_{2}\right)$, kepuasan kerja $\left(\mathrm{X}_{3}\right)$ berpengaruh positif terhadap kinerja karyawan $(\mathrm{Y})$. Berarti bila sistem seleksi, pelatihan, dan kepuasan kerja bernilai 0, maka nilai kinerja karyawan adalah sebesar 0,001

2. Nilai koefisien regresi $b_{1}=0,278$ menunjukan bahwa variabel sistem seleksi $\left(X_{1}\right)$ berpengaruh positif terhadap kinerja karyawan. Berarti, bila sistem seleksi naik, maka kinerja karyawan akan mengalami peningkatan..

3. Nilai koefisien regresi $b_{2}=0,280$ menunjukan bahwa variabel pelatihan $\left(X_{2}\right)$ berpengaruh positif terhadap kinerja karyawan. Artinya, bila pelatihan ditingkatkan satu satuan, maka kinerja karyawan akan mengalami peningkatan.

4. Nilai koefisien regresi $b_{3}=0,298$ menunjukan bahwa variabel kepuasan kerja $\left(X_{3}\right)$ berpengaruh positif terhadap kinerja karyawan. Hal ini, menunjukkan bahwa bila kepuasan kerja meningkat satu satuan, maka kinerja karyawan akan mengalami peningkatan.

Dari hasil analisis diperoleh nilai Multiple $\mathrm{R}=0,750$ dan nilai koefisien determinasi adjusted $r$ square $=0,537$ atau $(53,7 \%)$. Hal ini, menunjukan bahwa sistem seleksi, pelatihan, dan kepuasan kerja memiliki hubungan yang kuat dan pengaruh sebesar 53,7 persen terhadap kinerja karyawan. Dengan kata lain variabel sistem seleksi, pelatihan, dan kepuasan kerja memberi pengaruh sebesar 53,7\% terhadap kinerja karyawan pada PT. Lion Air Group Bandara Mutiara Sis Al-Jufri Palu sebelum pandemic Covid 19. Dan 46,3\% lainnya dipengaruhi oleh variabel-variabel yang tidak termasuk dalam penelitian ini, seperti disiplin kerja, kompensasi, kecerdasan emosional dan kecerdasan spiritual sebagaimana hasil penelitian menunjukkan bahwa karyawan yang memiliki kecerdasan emosional dan kecerdasan spiritual memiliki tingkat kreatifitas yang tinggi sehingga dapat meningkatkan kinerja karyawan (Suprapty 2017).

Sedangkan nilai $F_{\text {hitung }}=22.662>F_{\text {tabel }}$ 2,78. dengan nilai Sig. $F=0,000<\alpha=$ 0,05. Hasil ini, menunjukkan bahwa sistem seleksi, pelatihan dan kepuasan kerja secara simultan mempunyai pengaruh signifikan terhadap kinerja karyawan PT. Lion Air Group Bandara Mutiara Sis-Aljufri Palu sebelum Pandemic Covid 19. Demikian pula sebaliknya, berikut penjelasan dan pengaruhnya secara simultan dan parsial adalah sebagai berikut:

\subsection{Pengaruh Sistem Seleksi, Pelatihan dan Kepuasan Kerja Kayawan terhadap Kinerja Karyawan pada PT. Lion Air Group Bandara Mutiara Sis Al-Jufri Palu sebelum Pandemic Covid 19}

Diawal tahun 2019, seluruh dunia dan tak terkecuali di Indonesia sedang di landa wabah virus covid - 19 yang membuat sistem perekonomian dunia terpuruk dan berdampak signifikan terhadap beberapa industry tertentu. Tak dipungkiri juga dengan industry maskapai penerbangan, yang ada di Indonesia dan khususnya pada PT Lion Air Group Bandara Mutiara Sis Al-Jufri Palu. Data yang didapatkan oleh peneliti bahwa Asosiasi Transportasi Udara Internasional atau The International Air Transport Association (IATA) memprediksikan kerugian yang akan dialami oleh industry 
penerbangan hingga $\$ 113$ miliar disebabkan pandemi COVID-19. Terlebih Center of Aviation (CAPA) bahkan menduga industry maskapai di dunia mengalami gulung tikar pada akhir Mei 2020. Disebabkan cadangan kas perusahaan maskapai penerbangan mengalami deficit dengan cepat sedangkan ratusan unit pesawat parkir di hangar tanpa ada jadwal penerbangan.

Kondisi real PT Lion Air Group Bandara Mutiara Sis Al-Jufri Palu sekarang ini menyesuaikan dengan kebijakan yang dikeluarkan oleh maskapai penerbangan PT Lion Air Group. Dimana karyawan PT Lion Air Group Bandara Mutiara Sis Al-Jufri Palu di bulan April 2020 belum ada yang dirumahkan akan tetapi kebijakan yang diambil adalah meliburkan karyawan dan pegawai karena jadwal keberangkatan ditiadakan sampai batas waktu pemberitahuan selanjutnya dengan kemungkinan unpayment. Hal ini dapat dilihat dari, jumlah karyawan dan pegawai PT Lion Air Group Bandara Mutiara Sis Al-Jufri Palu sampai saat ini masih sama dengan jumlah populasi penelitian ini diawal tahun 2019 yaitu 136 karyawan dan pegawai PT Lion Air sebelum pandemic covid 19 mewabah di Kota Palu. Secara langsung juga berdampak pada system seleksi dan pelatihan karyawan terutama pelatihan simulator maupun pemeriksaan kesehatan bagi awak pesawat. Tidak adanya penerimaan atau rekruitmen karyawan karena pandemic covid 19, menyebabkan seleksi dan pelatihan karyawan atau pegawai belum terlaksana diawal kuartal tahun 2020.

Kepuasan karyawan PT Lion Air Group Bandara Mutiara Sis Al-Jufri Palu sebelum terjadinya pandemic covid 19 akan berbeda dengan saat terjadinya pandemic tersebut. Kebijakan maskapai penerbangan untuk merumahkan karyawan selama sebulan terjadinya pandemic adalah hal yang baru bagi mereka dan melakukan Work From Home (WFH) memerlukan adaptasi selama beberapa hari yang ditambah dengan kebijakan pemerintah melakukan pelarangan mudik serta kemungkinan unpayment bagi sebagian karyawan yang dirumahkan sehingga rata-rata maskapai penerbangan mengutamakan jasa pelayanan cargo atau pengiriman barang sebagai sumber penghasilan.

\subsection{Pengaruh Sistem Seleksi terhadap Kinerja Karyawan sebelum Pandemic Covid 19}

Dari hasil penelitian diatas diketahui koefisien regresi variabel sistem seleksi $\left(\mathrm{X}_{1}\right)$ sebesar 0,278 bertanda positif, artinya jika pendidikan, pengalaman kerja, kondisi fisik, dan kepribadian nilainya baik maka akan menigkatkan kinerja karyawan. Berdasarkan pada uji t yang telah dilakukan, hasilnya menunjukan nilai t-hitung sebesar 2.109 dan lebih besar dari pada nilai tabel yang sebesar 2.005 yang artinya variabel sistem seleksi berpengaruh positif terhadap kinerja karyawan pada PT. Lion Air Group Bandara Mutiara Sis-Aljufri Palu sebelum Pandemic Covid 19. Hasil dari penelitian ini juga menyatakan bahwa secara parsial sistem seleksi berpengaruh secara positif terhadap kinerja karyawan pada PT. Lion Air Group Bandara Mutiara Sis-Aljufri Palu sebelum Pandemic Covid 19.

Seleksi merupakan proses untuk mendapatkan dan mempergunakan informasi mengenai pelamar kerja untuk menentukan siapa yang seharusnya diterima menduduki posisi jangka pendek dan jangka panjang. Penempatan (placement) berkaitan dengan pencocokan seseorang dengan jabatan yang akan dipegangnya, berdasarkan pada kebutuhan jabatan dan pengetahuan, ketrampilan, kemampuan, preferensi, dan kepribadian kayawan tersebut. Prosedur seleksi yang cermat dan penempatan yang sesuai merupakan esensi dari pengelolaan sumber daya manusia dalam suatu 
organisasi. Bila masukan seleksi diperhatikan dengan seksama dan langkah-langkah dalam Seleksi diikuti secara benar maka akan menghasilkan karyawan baru yang memiliki kemampuan kerja yang tinggi, dengan demikian maka karyawan dapat melaksanakan seluruh tanggung jawab yang diberikan dengan kinerja yang tinggi pula, di dukung pula oleh pernyataan dari Samsudin (2009).

Kemudian dari hasil penelitian yang dilakukan oleh Sari (2010) yang melakukan penelitian mengenai sistem rekrutmen terhadap kinerja karyawan Outsourching pada PT. Persero Alih Daya Wilayah Sombagut dimana menemukan ada pengaruh yang positif dan signifikan antara seleksi dengan kinerja karyawan Outsourching. Sedangkan Andhika (2011) yang menemukan ada pengaruh yang signifikan antara metode penarikan dan seleksi terhadap kinerja karyawan, dan selain itu Andhika (2011) menemukan bahwa proses seleksi merupakan variabel yang paling dominan mempengaruhi kinerja karyawan pada Pengaruh Perekrutan Terhadap Kinerja Karyawan pada PT Perkebunan Nusantara III (Persero) Medan.

\subsection{Pengaruh Pelatihan terhadap Kinerja Karyawan sebelum Pandemic Covid 19}

Dari hasil penelitian di atas diketahui koefisien regresi variabel pelatihan $\left(\mathrm{X}_{2}\right)$ sebesar 0,280 bertanda positif, artinya jika peserta, materi, metode pelatihan dan sarana pelatihan. nilainya baik maka akan menigkatkan kinerja karyawan. Berdasarkan pada uji t yang telah dilakukan, hasilnya menunjukan nilai t-hitung sebesar 2.131 dan lebih besar dari pada nilai tabel yang sebesar 2.005 yang artinya variabel pelatihan berpengaruh positif terhadap kinerja karyawan pada PT. Lion Air Group Bandara Mutiara Sis-Aljufri Palu. Hasil dari penelitian ini juga menyatakan bahwa secara parsial pelatihan berpengaruh secara positif terhadap kinerja karyawan pada PT. Lion Air Group Bandara Mutiara Sis-Aljufri Palu sebelum Pandemic Covid 19.

Program pelatihan merupakan usaha untuk memperbaiki kinerja pegawai pada suatu pekerjaan tertentu yang sedang menjadi tanggung jawabnya. Adapun uraian dari Dessler (2009) yaitu, "pelatihan memberikan keterampilan yang dibutuhkan bagi karyawan baru atau karyawan yang sudah ada untuk menyelenggarakan pekerjaannya." cara agar dapat meningkatkan produktivitas kerja karyawan melalui peningkatan pelatihan yaitu memperhatikan kemampuan karyawan dengan kategori sesuai dengan permasalahan yang terjadi di perusahaan. Sementara itu, penelitian yang dilakuka oleh Suyoadi (2012) yang dilakukan di Kantor Bank Muamalat Cabang Semarang menyatakan pula bahwa kegiatan pelatihan yang dilakukan menunjukan pengaruh positif dan signifikan terhadap kinerja karyawan. Hal ini didukung juga dengan penelitian yang dilakukan oleh Lestari (2013) yang menyatakan bahwa pelatihan berpengaruh positif terhadap produktivitas kerja karyawan pada PT TASPEN (PERSERO) Kantor Cabang Denpasar.

\subsection{Pengaruh Kepuasan Kerja terhadap Kinerja Karyawan sebelum Pandemic Covid 19}

Dari hasil penelitian diatas diketahui koefisien regresi variabel kepuasan kerja $\left(\mathrm{X}_{3}\right)$ sebesar 0,298 bertanda positif, artinya jika menyenangi pekerjaannya, mencintai pekerjaannya, moral kerja, kedisiplinan dan prestasi kerja nilainya baik maka akan menigkatkan kinerja karyawan. Berdasarkan pada uji t yang telah dilakukan, hasilnya menunjukan nilai t-hitung sebesar 2.353 dan lebih besar dari pada nilai $t_{\text {tabel }}$ yang sebesar 2.005 yang artinya variabel kepuasan kerja berpengaruh positif terhadap kinerja 
karyawan pada PT. Lion Air Group Bandara Mutiara Sis-Aljufri Palu sebelum Pandemic Covid 19. Hasil dari penelitian ini juga menyatakan bahwa secara parsial kepuasan kerja berpengaruh secara positif terhadap kinerja karyawan pada PT. Lion Air Group Bandara Mutiara Sis-Aljufri Palu sebelum Pandemic Covid 19.

Faktor kepuasan kerja juga perlu mendapat perhatian. Adapun langkah penting dalam peningkatan kepuasan kerja dengan memperhatikan penentuan besar gaji yang diterima oleh karyawan agar sesuai dengan beban kerja, kondisi kerja yang mendukung, serta alat kerja yang digunakan dalam memproduksi kain. Hubungan antara karyawan dengan rekan sekerjanya perlu mendapatkan perhatian guna menghindari ketidak harmonisan hubungan dengan rekan sekerja

Kepuasan kerja bukanlah berarti seberapa keras atau seberapa baik seseorang bekerja, melainkan seberapa jauh seseorang menyukai pekerjaan tertentu. Kepuasan kerja berhubungan dengan perasaan atau sikap seseorang mengenai pekerjaan itu sendiri, gaji, kesempatan promosi atau pendidikan, pengawasan, rekan kerja, beban kerja, dan lain-lain.

"Kepuasan kerja adalah suatu bentuk perasaan emosional seseorang terhadap pekerjaannya. Semakin tinggi kemampuan karyawan dalam mengerjakan pekerjaan, semakin baik sikap dan minat karyawan terhadap pekerjaan maka kinerja karyawan semakin meningkat" Madegunastri dalam (Romel 2013). Dari defenisi kepuasan kerja di atas, penulis menyimpulkan bahwa kepuasan kerja adalah emosi atau perasaan positif yang muncul dari persepsi karyawan mengenai pekerjaan yang mereka lakukan.

\section{SIMPULAN, KETERBATASAN, DAN SARAN}

Berdasarkan hasil analisis dan pembahasan tentang pengaruh sistem seleksi, pelatihan dan kepuasan kerja terhadap kinerja karyawan pada PT. Lion Air Group Bandara Mutiara Sis Al-Jufri Palu sebelum Pandemic Covid 19, maka dapat ditarik kesimpulan sebagai berikut :

1. Sistem seleksi, pelatihan dan kepuasan kerja secara simultan berpengaruh positif dan signifikan terhadap kinerja karyawan pada PT. Lion Air Group Bandara Mutiara Sis Al-Jufri Palu sebelum Pandemic Covid 19.

2. Hasil pengujian ini menunjukan bahwa secara parsial sistem seleksi memiliki pengaruh positif dan signifikan terhadap kinerja karyawan pada PT. Lion Air Group Bandara Mutiara Sis Al-Jufri Palu sebelum Pandemic Covid 19.

3. Hasil pengujian ini menunjukan bahwa secara parsial pelatihan memiliki pengaruh positif dan signifikan terhadap kinerja karyawan pada PT. Lion Air Group Bandara Mutiara Sis Al-Jufri Palu sebelum Pandemic Covid 19.

4. Hasil pengujian ini menunjukan bahwa secara parsial kepuasan kerja memiliki pengaruh positif dan signifikan terhadap kinerja karyawan pada PT. Lion Air Group Bandara Mutiara Sis Al-Jufri Palu sebelum Pandemic Covid 19

Dari hasil penelitian yang memperlihatkan bahwa sistem seleksi, pelatihan dan kepuasan kerja memiliki pengaruh positif dan signifikan terhadap kinerja karyawan, maka Untuk memaksimalkan kinerja karyawan pada PT. Lion Air Group Bandara Mutiara Sis Al-Jufri Palu sebelum Pandemic Covid 19, disarankan:

1. Pihak manajemen pelu melakukan sistem seleksi yang ketat dengan memperhatikan kemampuan dan kemauan kerja karyawan yang tinggi, sesuai kebutuhan kerja yang diperlukan perusahaan dan melakukan penempatan sesuai dengan keahliannya. 
2. Dalam pelaksanaan pelatihan, materi-materi pelatihan perlu disesuaikan dengan tugas dan tanggung jawab yang dibebankan kepada karyawan, agar keterampilan dan keahlian kerja yang dimiliki sesaui dengan tugasnya.

3. Pihak manajemen juga, perlu meningkatkan kemauan dan mendorong rasa tanggung jawab karyawan dalam melaksanakan tugasnya, dengan menciptakan kepuasan kerja bagi karyawan terutama saat melakukan Work Form Home dimasa pandemi covid 19 berlangsung.

4. Kepuasan karyawan PT Lion Air Group Bandara Mutiara Sis Al-Jufri Palu sebelum terjadinya pandemic covid 19 akan berbeda dengan saat terjadinya pandemic tersebut sehingga untuk peneliti selanjutnya perlu melakukan penelitian kembali tentang Kepuasan karyawan PT Lion Air Group Bandara Mutiara Sis Al-Jufri Palu setelah terjadinya pandemic covid 19

Karena penelitian ini terbatas pada data kuesioner dan hanya pada tiga variabel saja, sementara masih terdapat banyak variabel lain yang dapat mempengaruhi kinerja karyawan, seperti disiplin kerja, motivasi kerja, dan kompensasi. Sehingga kepada peneliti lain diharapkan dapat memasukkan metode wawancara terstruktur dalam pengumpulan dan memperluar pada variabel lain, apalagi ketiga variabel tersebut baru memberi kontribusi sebesar 53,7 persen. Artinya masih terdapat 43,6 persen pengaruh faktor lain.

\section{DAFTAR PUSTAKA}

Andhika, E. 2011. Pengaruh Perekrutan Terhadap Kinerja Karyawan pada PT Perkebunan Nusantara III (Persero) Medan. Skripsi, Departemen Manajemen. Fakultas Ekonomi, Universitas Sumatera Utara, Medan.

Dessler, G. 2009. Manajemen Sumber Daya Manusia. Jakarta: PT INDEKS.

Hasibuan, M. S. P. 2008. Manajemen Sumber Daya Manusia. Jakarta: PT Bumi Aksara.

Lestari, A. 2013. Pengaruh Pelatihan Kerja, Lingkungan Kerja Fisik, Serta Motivasi Terhadap Produktivitas Kerja Pegawai Pada PT. TASPEN (PERSERO) Kantor Cabang Denpasar. Jurnal Manajemen 2 (1):12-14.

Mangkunegara. 2006. Manajemen Sumber Daya Manusia. Bandung: PT Remaja Rosda Karya.

2009. Perilaku Konsumen. Bandung: Refika.

Nitisemito, A. S. 2008. Manajemen Personalia Manajemen Sumber Daya Manusia. Jakarta: Ghalia Indonesia.

Rangkuti, F. 2007. Manajemen Persediaan Aplikasi di Bidang Bisni. Jakarta: Raja Grafindo Persada.

Romel, D. 2013. Pengaruh Karakteristik Individu Terhadap Kepuasan Kerja dan Implikasinya pada Kinerja Karyawan di UNIKOM. Tugas Akhir, Fakultas Ekonomi, Universitas Komputer Indonesia, Bandung.

Samsudin, S. 2009. Manajemen Sumber Daya Manusia. Bandung: Pustaka Setia.

Sari, F. Y. 2010. Pengaruh Sistem Rekrutmen Terhadap Kinerja Karyawan Outsourcing Pada PT. Personel Alih Daya Wilayah Sumbagut. Skripsi, Fakultas Ekonomi, Universitas Sumatera Utara, Medan.

Simamora. 2004a. Manajemen Sumber Daya Manusia. Yogyakarta: STIE YKPN. 
Simamora, H. 2004b. Manajemen Sumber Daya Manusia Edisi Ketiga. Yogyakarta: STIE YKPN.

Sunyoto, D. 2012. Manajemen Sumber Daya Manusia. Yogyakarta: CAPS: Center for Academic Publishing Service.

Suprapty, R. 2017. Pengarh Kecerdasan Emosional terhadap Komunikasi Interpersonal Karyawan dengan Nasabah pada PT Bank BTPN Tbk Cabang Palu. Wacana Equilibrium:1-22.

Suyoadi, Y. 2012. Pengaruh Pelatihan dan Kepuasan Kompensasi Terhadap Kinerja Karyawan pada PT Bank Muamalat Indonesia Cabang Semarang. Skripsi, Fakultas Ekonomika dan Bisnis, Universitas Diponegoro, Semarang. 